\title{
Epidemiology of penicillinase-producing Neisseria gonorrhoeae in Singapore*
}

\author{
V S RAJAN, T THIRUMOORTHY, AND N J TAN \\ From the Middle Road Hospital, Singapore, Republic of Singapore
}

SUMMARY The number of infections with penicillinase-producing Neisseria gonorrhoeae (PPNG) strains in Singapore has risen from three in 1976 to 1792 in 1979. In the latter year they $\mathscr{\sigma}^{\circ}$ formed $19 \cdot 2 \%$ of all infections with gonorrhoea, and 1280 of the strains isolated were from $\stackrel{?}{=}$ female prostitutes. The prevalence of PPNG infections is analysed according to the different $\mathcal{G}$ sections of the community and racial groups. Despite energetic control measures PPNG strains are $\omega$ not being contained within Singapore. Thus global dissemination from such a busy port and $\vec{\infty}$ tourist centre is a real danger.

\section{Introduction}

Since their first recognition early in $1976^{12}$ penicillinase-producing strains of Neisseria gonorrhoeae (PPNG) have been reported in more than 30 countries based on bacteriological or epidemiological evidence. This widespread prevalence threatens the success of standard single-dose penicillin treatment regimens for gonorrhoea.

PPNG strains were first isolated in Singapore late in $1976^{3}$ and have been increasing ever since. Singapore is one of the world's busiest tourist and business centres. Because of its geographical location and economic development it serves as a link between several parts of South-east Asia and the rest of the world. In 1979, just over two million visitors from all parts of Asia, Europe, Australasia, and North America disembarked in Singapore. This paper presents (1) the epidemiological data and trends; and (2) the control measures instituted.

\section{Epidemiological data}

The data used in this paper were obtained mainly from Middle Road Hospital (the main dermatovenereological centre in Singapore) and other government medical institutions. All results have been confirmed by bacteriological culture studies.

\footnotetext{
*Paper read at the 30th General Assembly of the International Union against the Venereal Diseases and Treponematoses, East Berlin, June 1980

Address for reprints: Dr V S Rajan, Middle Road Hospital, Singapore 7, Republic of Singapore

Accepted for publication 13 October 1980
}

The data from the private medical sector, where a

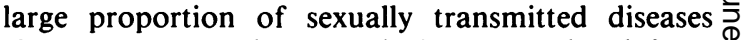
(STDs) are treated, can only be extrapolated from crude figures.

In 1979,6922 cases were reported by private: practitioners, of which 6587 were men and 335 women; most of these diagnoses were not based on bacteriological studies. This gives a total of 16254 응

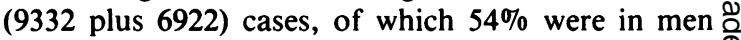
and $45.5 \%$ in women. A large proportion of the men $\stackrel{\perp}{2}$ with gonorrhoea thus seek treatment from private $\overrightarrow{\overrightarrow{0}}$ sources.

The incidence of gonorrhoea by sex in prostitutes and the general public in Singapore from 1975 to 1979 is given in table I. In 1975 the male-to-female on ratio was $3: 1$; by 1979 this had reversed to $1: 3$. This was a result of the introduction of control $\exists$ measures within the prostitute population late in 1976.

From 1977 onwards, female prostitutes provided over $70 \%$ of the reported cases of PPNG and the male general public only $20 \%$.

\section{TRENDS OF PPNG INFECTIONS}

The incidence of PPNG infections has steadily $N$ increased from three cases in 1976 to 1792 in 1979, N when they comprised $19 \cdot 2 \%$ of all gonococci isolated (table I); monthly returns in 1980 do not show any fall. This increase in the number of PPNG infections has occurred despite bacteriological surveillance and $\mathscr{\Phi}$ free treatment.

There has been a significant $(\mathrm{P}<0 \cdot 01)$ decrease in $\frac{0}{0}$ the number of non-PPNG cases, from 8036 in $1978 \stackrel{\mathbb{\Phi}}{\mathbb{D}}$ to 7540 in 1979 . In this population it appears that the $\frac{\rho}{\mathbb{Q}}$ bacteriological balance between PPNG and nonPPNG strains has not stabilised. 
TABLE I Incidence of gonorrhoea, and proportion of infections caused by PPNG, in the general public and prostitutes by sex in Singapore (1975-79)

\begin{tabular}{|c|c|c|c|c|c|}
\hline & \multicolumn{5}{|l|}{ Year } \\
\hline & 1975 & 1976 & 1977 & 1978 & 1979 \\
\hline $\begin{array}{l}\text { Total No of } \\
\text { cases of gonorrhoea } \\
\text { Men }\end{array}$ & 2997 & 4076 & 7668 & 9052 & 9332 \\
\hline $\begin{array}{l}\text { General public } \\
\text { Prostitutes }\end{array}$ & $\begin{array}{r}2146 \\
67\end{array}$ & $\begin{array}{r}1979 \\
79\end{array}$ & $\begin{array}{r}1703 \\
138\end{array}$ & $\begin{array}{r}1752 \\
290\end{array}$ & $\begin{array}{r}1796 \\
469\end{array}$ \\
\hline $\begin{array}{l}\text { Women } \\
\text { General public } \\
\text { Prostitutes }\end{array}$ & $\begin{array}{l}394 \\
390\end{array}$ & $\begin{array}{r}275 \\
1743\end{array}$ & $\begin{array}{r}230 \\
5597\end{array}$ & $\begin{array}{r}237 \\
6773\end{array}$ & $\begin{array}{r}256 \\
6811\end{array}$ \\
\hline $\begin{array}{l}\text { Non-PPNG strains }(\%) \\
\text { PPNG strains (\%) } \\
\text { Men (general public) } \\
\text { Women (general public) }\left(\%{ }^{*}\right) \\
\text { Men (prostitutes) } \\
\text { Women (prostitutes) }\left(\%^{*}\right)\end{array}$ & $2997(100)$ & $\begin{array}{rr}4073 & (99 \cdot 9) \\
3 & (0 \cdot 07) \\
1 & \end{array}$ & $\begin{aligned} 7646 & (91 \cdot 7) \\
22 & (0 \cdot 29) \\
8 & \\
3 & (1 \cdot 3) \\
11 & (0 \cdot 2)\end{aligned}$ & $\begin{array}{l}8036(88 \cdot 8) \\
1016(11 \cdot 2) \\
211 \\
28(11 \cdot 8) \\
9 \\
768(11 \cdot 3)\end{array}$ & $\begin{array}{r}7540(80 \cdot 8) \\
1792(19 \cdot 2) \\
397 \\
82(32 \cdot 1) \\
33 \\
1280(18 \cdot 8)\end{array}$ \\
\hline
\end{tabular}

*\% of total No of cases of gonorrhoea

The incidence of PPNG infections in prostitutes and the general public between 1975 and 1979 is shown in table I. Female prostitutes contributed $\mathbf{7 2} \cdot \mathbf{7 \%}$ of PPNG cases and over $70 \%$ of all infections with gonorrhoea. The percentage of PPNG infections in both men and women with gonorrhoea in 1979 was $19 \cdot 2 \%$ (table I); that in the female general public with gonorrhoea, however, has risen to $32 \%$. The reason for this sudden rise cannot be explained. It may be due to a bias in the selection of this subpopulation. It does imply an increasing occurrence of ophthalmia neonatorum and pelvic infections due to PPNG strains, which is reflected by the monthly returns for 1980 .

\section{Demographic features}

\section{AGE AND SEX}

In the general public there were 172 male cases of PPNG infection in 1978 in the age group 15-29 years; these formed $81.5 \%$ of PPNG infections in this group and represented $17 \%$ of all PPNG infections in that year. In the general public in 1979 this age group provided $76.5 \%$ of PPNG infections in men and $17 \%$ of all PPNG infections for that year. PPNG strains were initially confined mainly to the $15-29$ age group, whose members were naturally sexually more active and promiscuous. As the prevalence of PPNG strains increased, infections have spread to the older members of the population. This trend was also noted in the female general public and in female prostitutes. Of all female PPNG infections $64 \cdot 2 \%$ occurred in the $15-29$ age group and constituted $1.8 \%$ of all such infections in 1978. In female prostitutes $69 \%$ of PPNG infections in 1978 and $62.6 \%$ in 1979 occurred in the $20-29$ age group.
TABLE II Incidence of PPNG infections by race in Singapore (1978-79)

\begin{tabular}{|c|c|c|c|c|c|}
\hline \multirow[b]{3}{*}{ Race } & \multirow{3}{*}{$\begin{array}{l}\text { \% of total } \\
\text { population }\end{array}$} & \multicolumn{4}{|c|}{ Incidence of PPNG infections } \\
\hline & & \multicolumn{2}{|c|}{1978} & \multicolumn{2}{|l|}{1979} \\
\hline & & No & $\%$ & No & $\%$ \\
\hline Chinese & 73 & 786 & 77 & 1286 & 72 \\
\hline Malay & 15 & 179 & 18 & 348 & 19 \\
\hline Indian & 7 & 48 & 5 & 114 & 6 \\
\hline Others & 5 & 3 & & 20 & \\
\hline Unknown & & & & 24 & \\
\hline
\end{tabular}

This group contributed $52 \%$ of all PPNG infections in Singapore in 1978 and $45 \%$ in 1979 and thus forms the high-risk group among female prostitutes.

RACE

The incidence of PPNG infections by race for 1978 and 1979 is shown in table II; this reflects the racial composition of the Republic.

OCCUPATION

The semi-skilled and unskilled workers and armed forces together provided $64 \%$ of the PPNG infections in the general public in 1979 (table III). To a

TABLE III Incidence of PPNG infections according to occupation in the general public (1979)

\begin{tabular}{lrcr}
\hline Occupation & Men & Women & Total \\
\hline Lower professional & 19 & & 19 \\
Skilled worker & 48 & 1 & 49 \\
Semi-skilled worker & 134 & 17 & 151 \\
Unskilled worker & 69 & 3 & 72 \\
Armed forces & 83 & & 83 \\
Jobless & 29 & 8 & 37 \\
Student & 5 & 1 & 6 \\
Unknown & 6 & 19 & 25 \\
Seaman & 4 & 33 & 4 \\
Housewife & & 82 & 479 \\
Total & 397 & & \\
\hline
\end{tabular}


large extent this reflects the economic class of patients attending government medical institutions. There is also a high proportion of immigrant labourers, who are single and young, in the semiskilled and unskilled group.

\section{MARITAL STATE}

Of patients with PPNG infections in the general public $71 \%$ were single and $27 \%$ married. Thus, men who are single, in the 15-29 age group and in the semi-skilled and unskilled labour group, have the highest risk of acquiring PPNG infections.

\section{Transmission and spread of PPNG infections}

PLACE OF CONTACT

In $1979,85 \%$ of patients cited their place of infection as Singapore; in 1978 and 1977 the figures were $90 \%$ and $\mathbf{7 3 \%}$ respectively (table IV). Except for Thailand, which contributed slightly less than $10 \%$ of infections in 1979, there seems to be no significant contribution by neighbouring countries.

TABLE IV Reported source of PPNG infections in men and women (general public) according to countries (1976-79)

\begin{tabular}{lcrrr}
\hline Country & 1976 & 1977 & 1978 & 1979 \\
\hline Singapore & 1 & 8 & 217 & 408 \\
Malaysia & & 2 & 14 & 15 \\
Thailand & & & 4 & 47 \\
Indonesia & & 1 & 1 & 1 \\
Philippines & & 11 & 2 & 4 \\
Taiwan & 1 & & 239 & 479 \\
Total & & & & \\
\hline
\end{tabular}

\section{SOURCE}

Professional prostitutes were cited as the primary contacts in about $72 \%$ of cases in 1978 and in $66.8 \%$ in 1979 (table V). Boy-friends and husbands contributed about $10 \%$ of infections in both years and were probably the source of infection for the female general public.

\section{LOCATION}

The first three cases of PPNG infections in prostitutes were found towards the end of 1976 in districts 8 and 14 , the main red-light districts in $\frac{\mathbb{D}}{\stackrel{D}{2}}$ Singapore. The next year a small increase in $\underline{\underline{S}}$. incidence was noted, but the infection was still $\stackrel{\text { ? }}{\text {. }}$ confined to these districts. In 1978 and 1979, however, with a further rise in incidence, there was ao spill-over to other red-light districts $(2,9,10,15$, and 27).

\section{CONTACT TRACING}

The results of contact tracing of PPNG cases in the male and female general public in 1979 are given in $\vec{O}$ table VI. The overall success rate was $51 \%$. Of the $\vec{\overrightarrow{ }}$ $49 \%$ (238 out of 479) who were untraceable, 147 were ${ }_{\sigma}$ female prostitutes, a major contribution since these $\stackrel{0}{=}$. formed a larger proportion of the total cohort. In $i$ fact the success rate of contact tracing in this group ${ }_{\omega}$ was $54 \%$, which is higher than the overall $51 \%$. But because of their high risk of spreading infection $\mathcal{O}_{\infty}$ $(8-12$ clients per night) they are an important group 을 in the control of gonorrhoea.

It is of interest that non-PPNG strains were $\vec{c}$ isolated from $15 \%$ of primary contacts, which is $30 \%$ of all cases traced (table VI). This figure was consistent throughout the various social groups; $29 \%$ of $\infty$ traced prostitutes, $27 \%$ of traced wife/girl-friends, $\stackrel{-}{-}$ and $30 \%$ of traced husband/boy-friends, and leads to the postulation that infections with PPNG and non-PPNG strains occurred concomitantly. It also raises the question whether the ability to produce penicillinase could be transient in a different host $\stackrel{\mathbb{D}}{\mathscr{D}}$ environment. What role the widespread prophylactic $\overrightarrow{\vec{B}}$ use of antibiotics plays in the generation of this 3 transient state remains unanswered. Fifty-five

TABLE V Primary contacts of PPNG cases according to occupation/social status in Singapore (1978-79)

\begin{tabular}{|c|c|c|c|c|}
\hline \multirow[b]{2}{*}{ Source } & \multicolumn{2}{|c|}{1979} & \multicolumn{2}{|c|}{1978} \\
\hline & No & $\%$ & No & $\%$ \\
\hline $\begin{array}{l}\text { Female prostitute } \\
\text { Male prostitute }\end{array}$ & $\begin{array}{r}316 \\
4\end{array}$ & $66 \cdot 8$ & 156 & 72 \\
\hline Wife/girl-friend & 27 & $5 \cdot 6$ & 9 & 4 \\
\hline Boy-friend/husband & 56 & $11 \cdot 7$ & 22 & 10 \\
\hline Casual girl-friend & 26 & $5 \cdot 4$ & 15 & 7 \\
\hline Unknown/denies & 50 & $10 \cdot 5$ & 15 & 7 \\
\hline Total & 479 & 100 & 217 & 100 \\
\hline
\end{tabular}

TABLE VI Results of primary contact tracing of PPNG cases in men and women (general public) in Singapore (1979)

\begin{tabular}{|c|c|c|c|c|c|}
\hline Source & Non-PPNG & $P P N G$ & No $S T D$ & Unable to trace & Total \\
\hline Female prostitute & 50 & 69 & 50 & 147 & 316 \\
\hline Male prostitute & 1 & 1 & & 2 & 4 \\
\hline Wife/girl-friend & 6 & 14 & 2 & 5 & 27 \\
\hline Boy-friend/husband & 14 & 29 & 3 & 10 & 56 \\
\hline Casual girl-friend & 1 & & & 25 & 26 \\
\hline Unknown/denies & & & & 50 & 50 \\
\hline Total No & 72 & 113 & 56 & 238 & 479 \\
\hline$\%$ Of total & 15 & 24 & 12 & 49 & 100 \\
\hline
\end{tabular}


primary contacts traced did not show any evidence of STDs; 50 of these were prostitutes.

\section{Control measures}

The general aspects of STD control in Singapore have been described by Rajan. ${ }^{4}$ Measures aimed at limiting the spread of PPNG strains include intensive bacteriological surveillance, effective treatment, determined contact tracing, and control of the infection in prostitutes.

All patients with suspected gonorrhoea have smears and cultures performed. All isolates of $N$ gonorrhoeae are routinely screened for penicillinase production by the iodometric method. ${ }^{5}$ When a penicillinase-producing strain is identified a state of epidemiological alert is declared. The laboratory informs the epidemiological control unit immediately and contact tracers are sent out at once to contact and advise the patient to seek immediate treatment.

For the treatment of PPNG infections we favour the use of a single 2-g dose of kanamycin intramuscularly. This aminoglycoside, which is relatively cheap in Singapore, has given a cure rate of $98 \% .^{6}$ Treated patients are advised to come back for followup, when smears and cultures are carried out on the third, seventh, and fourteenth day to confirm cure.

All patients with PPNG infections are interviewed about their sexual partners, and rapid contact tracing is undertaken. Contacts are investigated and treated if found to be infected. Epidemiological treatment is not routinely given, but if the epidemiological evidence strongly suggests an infection the contact is treated after the relevant tests have been performed.

Prostitutes continue to be the main source of infections, and a system to limit the incidence of infection in this group has been developed. Towards the end of 1976 a medical scheme incorporating the assistance of the police department, computer services department, laboratory and clinical services, and general practitioners was launched. Prostitutes are required to register with this scheme and to present regularly for periodic examinations and treatment if found to be infected. Compliance is ensured by persuasion, motivation, and the occasional use of subtle legal pressure. About 5000 prostitutes are currently in the scheme, and the reversal of the male-to-female ratio for gonorrhoea to $1: 3$ gives clear proof of the success of this scheme.

\section{Conclusions}

It is obvious, however, that despite the above measures we are unable to contain PPNG infections in Singapore. As infection by these strains becomes more prevalent, the standard single-dose penicillin treatment regimen for gonorrhoea will become progressively less efficacious and will eventually need to be changed. This will necessarily mean the use of more costly drugs, such as the aminoglycosides. There is also the additional possibility of increasing resistance to these agents with increased usage. Yet another potential consequence of such a change is an increase in the incidence of infectious syphilis, as the use of aminoglycosides may not abort incubating syphilis.

With the spread of PPNG, an increase in ophthalmia neonatorum and pelvic infections due to PPNG strains ${ }^{78}$ can be expected. There are, as yet, no established recommended treatment schedules for complicated gonococcal infections due to PPNG. The cost of using cefuroxime or other cephalosporins will prove prohibitive for a developing country, while the need to use an aminoglycoside in multiple doses will increase the risk of eighth nerve damage and renal toxicity.

Finally, and most importantly, the establishment of PPNG in a busy port and tourist centre like Singapore means that the risk of global dissemination constitutes a real danger.

\section{References}

1. Phillips I. $\beta$-lactamase-producing penicillin-resistant gonococci. Lancet 1976; ii:656.

2. Ashford WA, Golash RG, and Hemming VG. Penicillinaseproducing Neisseria gonorrhoeae. Lancet 1976; ii: 657.

3. Rajan VS, Sng EH, Khoo R, et al. Beta-lactamase strains of gonococci in Singapore. Asian J Infect Dis 1977; 1:62.

4. Rajan VS. Sexually transmitted diseases on a tropical island. $\mathrm{Br}$ $J$ Vener Dis 1978;54:141-3.

5. Catlin BW. lodometric detection of Haemophilus influenzae beta-lactamase: rapid presumptive test for ampicillin resistance. Antimicrob Agents Chemother 1975; 7:265.

6. Rajan VS, Pang R, Tan NJ, Sng EH. Kanamycin in the treatment of penicillinase-producing gonococcal infection. Asian $J$ Infect Dis 1979;3:37.

7. Pang R, Teh LB, Rajan VS, et al. Gonococcal ophthalmia neonatorum caused by beta-lactamase-producing Neisseria gonorrhoeae. Br Med J 1979; i: 380.

8. McCarthy T, Salmon Y, Choo HT, et al. The clinical presentation of gonorrhoea in obstetrical and gynaecological practice. Singapore J Obstet Gynaecol 1977; 10:49-54. 